\title{
Flexible Bronchoscopy as a Diagnostic and Therapeutic Method in Patients with Tracheobronchial Foreign Body
}

\author{
Marcelo Fouad Rabahi' ${ }^{1}$, Luísa Oliveira de Paiva ${ }^{2}$, Mariana Almeida de Castro², \\ Orlando Roberto da Silva Neto ${ }^{2}$ \\ ${ }^{1}$ Medical Clinic Department, Medical School, Federal University of Goias, Goiania (GO), Brasil \\ ${ }^{2}$ Medicine School, Federal University of Goias, Goiania (GO), Brasil \\ Email: luisaoliveirapaiva@gmail.com
}

Received 17 April 2014; revised 16 May 2014; accepted 15 June 2014

Copyright (C) 2014 by authors and Scientific Research Publishing Inc.

This work is licensed under the Creative Commons Attribution International License (CC BY). http://creativecommons.org/licenses/by/4.0/

(c) (i) Open Access

\begin{abstract}
Objective: To analyze bronchoscopy as a diagnostic and therapeutic method in patients with tracheobronchial foreign body. Methods: We analyzed reports of flexible bronchoscopy with diagnose of tracheobronchial foreign body performed from 2003 to 2013 in São Salvador Hospital, in Goiania, capital of Goiás. The analysis was based on: sex and age of the patients, airways and foreign body characteristics, foreign body localization, success rate and rate of bleeding. We calculated the frequencies after analyzing the data. Results: We analyzed 26 reports of the studied period and found that $57.7 \%$ of the patients were male with median age of 58.83 years old $(+-13.79)$. The airways characteristics were normal in most of the cases. Sputum wasn't found in $57.69 \%$ of the cases. Foreign bodies were located in right bronchus in $88.46 \%$ of the cases, and the extraction of them was successful in $80.76 \%$ of the cases. The absence of bleeding was reported in $96.15 \%$ of the cases. Conclusions: Flexible bronchoscopy is a notably successful method in management of tracheobronchial foreign bodies. Airways characteristics aren't good indicatives of FB's presence, once they are normal in most of the times.
\end{abstract}

\section{Keywords}

Flexible Bronchoscopy, Foreign Bodies, Airway Management

\section{Introduction}

Tracheobronchial Foreign Body (TFB) aspiration has higher frequency among children, although it can occur at 
any stage in life. When in adults it is mostly related to accidental aspiration of working tools and bone fragments, advanced age and unconsciousness, and is considered an uncommon situation [1]-[5].

The Gold standard treatment for foreign body (FB) aspiration remains rigid bronchoscopy. However, in many departments flexible bronchoscopy has been the procedure of choice for diagnosis and treatment of FB aspiration in adult population [6].

Flexible bronchoscopy is possibly an outpatient procedure and can be performed under conscious sedation, what involves lower costs, same effectiveness and safety than rigid bronchoscopy. Therefore, flexible bronchoscopy is a great option to treat TFB. It remarkably increased the visible range especially in the upper lobes where the sub-segmental bronchi up to the IV order of division can be visualized. This is possible even when the bronchi are distorted, displaced or with stenosis. In addition, material can be obtained from bronchi under direct vision by using brushes or biopsy curettes [6]-[9].

The objective of our study was to analyze flexible bronchoscopy as diagnostic and therapeutic method in patients with TFB.

\section{Methods}

We performed this study in São Salvador Hospital, in Goiania, capital of Goiás. This hospital is not a reference in pediatric care, and most of the bronchoscopy procedures were performed in adults.

All bronchoscopic procedures were performed by the same specialist. A Pentax VB-1830T2 fiberoptic bronchoscope (Asahi Optical Co., Tokyo, Japan) was used. Patients received sedation with midazolam and fentanyl, followed by topical anesthesia with 10\% lidocaine spray and 2\% lidocaine solution (maximum dose, 20 mL). The device was inserted orally, with the patient in the supine position.

We studied the reports of flexible bronchoscopy performed from 2003 to 2013 that found TFB. With these reports we could analyze patients' age and sex, the nature of the FB found, their localizations and patients' respiratory trees.

Then, we calculated the frequencies of the data analyzed.

\section{Results}

Reviewing medical records of the set period, we found 26 cases of FB in airways. These medical records also made it possible to study the airways of the patients, as well as the localization and the nature of the FB. Of the 26 patients analyzed, $42.30 \%(n=11)$ were female and $57.7 \%(n=15)$ were male, with ages ranging from 11 to 90 years, with median age of $58.83( \pm 13.79)$ (Table 1$)$. The distribution of patients by age was: $3.84 \%(n=1)$ between 11 - 20 years old; 3.84\% $(n=1)$ between 21 - 30 years old; 7.69\% $(n=2)$ between 31 - 40 years old; $11.53 \%(n=3)$ between 41 - 50 years old; $11.43 \%(n=3)$ between 51 - 60 years old; 30.76\% $(n=8)$ between 61 - 70 years old; $19.23 \%(n=5)$ between 71 - 80 years old and 3.84\% $(n=1)$ between 81 - 90 (Table 2). In 2 cases $(7.69 \%)$ the age was ignored in the report (Table 2 ).

The reports of the examinations performed could infer the presence or not of sputum and also analyze the following organs: larynx, vocal cords, trachea, carina and the bronchi.

We found sputum in $38.46 \%(n=10)$ of the cases and could not find any sputum in $57.69 \%(n=15)$ of them. It was ignored the description of sputum or its absence in the reports in $3.84 \%(n=1)$ of the cases. Of the $38.46 \%$ $(n=10)$ cases with sputum, 70\% $(n=7)$ were muco-purulent and 30\% $(n=3)$ were mucoid (Table 3$)$.

The larynx was described as normal in $69.23 \%(n=18)$ of the cases and hyperemic in $23.07 \%(n=6)$. It was ignored its description in $7.69 \%(n=2)$ of the reports. The vocal cords were described as normal in $88.46 \%(n=$ $23)$ of the cases and paretic in $3.84 \%(n=1)$. It was ignored its description in $7.69 \%(n=2)$ of the cases. The trachea was normal in $61.53 \%(n=16)$ of the cases, hyperemic in $23.07 \%(n=6)$, tortuous in $3.84 \%(n=1)$,

Table 1. Patient's sex.

\begin{tabular}{ccc}
\hline & \multicolumn{3}{c}{ Patients $n=26$} \\
\cline { 3 - 3 } Sex & $\mathbf{n}$ & $\%$ \\
\hline Female & 15 & 57.7 \\
\hline
\end{tabular}


Table 2. Patient's age distribution.

\begin{tabular}{ccc}
\hline Age & \multicolumn{3}{c}{ Patients $n=26$} \\
\cline { 2 - 3 } $11-20$ & $\mathbf{n}$ & $\%$ \\
$21-30$ & 1 & 3.84 \\
$31-40$ & 1 & 3.84 \\
$41-50$ & 2 & 7.69 \\
$51-60$ & 3 & 11.53 \\
$61-70$ & 3 & 11.53 \\
$71-80$ & 8 & 30.76 \\
$81-90$ & 5 & 19.23 \\
Ignored & 1 & 3.84 \\
\hline
\end{tabular}

Table 3. Sputum found or not found in the airways and its characteristics.

\begin{tabular}{ccc}
\hline Sputum & \multicolumn{2}{c}{ Patients $\mathrm{n}=26$} \\
\cline { 2 - 3 } Found & $\mathbf{n}$ & $\mathbf{3 8 . 4 6}$ \\
Muco-purulent & $\mathbf{1 0}$ & 26.92 \\
Mucoid & 7 & 11.54 \\
Not found & 3 & $\mathbf{5 7 . 6 9}$ \\
Ignored & $\mathbf{1 5}$ & $\mathbf{3 . 8 4}$ \\
\hline
\end{tabular}

with stenosis in 3.84\% $(\mathrm{n}=1)$ and had hypotrophy in 3.84\% $(\mathrm{n}=1)$ of the cases. It was ignored its description in $3,84 \%(n=1)$ of the cases. The carina was described as narrow, mobile and centered in $88.46 \%(n=23)$ of the cases, in just one case (3.84\%) it was skewed to the right and it was not described in $7.69 \%(\mathrm{n}=2)$ of them (Table 4).

In regard to the localization of the FB in the respiratory tree, $88.46 \%(n=23)$ were in the right bronchus. In these cases, the right bronchus was described as normal in $15.38 \%(n=4)$, hyperemic in $65.38 \%(n=17)$ and with stenosis in $7.69 \%(n=2)$. Also in these cases with the FB in the right bronchus, the left bronchus was described as normal in $65.38 \%(n=17)$ of them and in $23.07 \%(n=6)$ of the cases both the right and left bronchi were hyperemic (Table 5).

FB was found in the left bronchus only in 3.84\% $(n=1)$ of the cases, and in this one it was ignored the description of this bronchus in the report. At last, FB were found in the trachea in $7.69 \%(n=2)$ of the cases, in one of them the trachea was described as normal and in the other it was with stenosis (Table 5).

Concomitant to flexible bronchoscopy, additional procedures were done. Endobronchial biopsy was done in $3.84 \%(n=1)$ of the cases and bronchoalveolar lavage in $30.79 \%(n=8)$.

Success in the procedure happened in $80.76 \%(\mathrm{n}=21)$ of the cases and did not happen in $19.23 \%(\mathrm{n}=5)$. In two of these cases were necessary rigid bronchoscopy to remove the FB, where was found stenosis of trachea in one case and stenosis of right bronchus in another one. In other two cases, the success were achieved in the second procedure of flexible bronchoscopy, and in the last one of the cases there wasn't enough time to try another procedure, because of posterior pacient's death, not related to the procedure or FB. Bleeding was absent in $96.15 \%(n=25)$ of the procedures and ignored in the reports in 3.84\% $(n=1)$ of them.

Many of the reports described the nature of the FB found. Of the $26 \mathrm{FB}, 34.61 \%(\mathrm{n}=9)$ became from animal nature (fragments of meat or bones), $34.61 \%(n=9)$ were stalks, fruits or seeds, $11.53 \%(n=3)$ were teeth, $11.53 \%(n=3)$ were metallic and 7.69\% $(n=2)$ had its origins ignored (Figure 1$)$. FB from animal nature 
Table 4. Airways characteristics.

\begin{tabular}{|c|c|c|}
\hline \multirow{2}{*}{$\begin{array}{c}\text { Characteristics } \\
\text { Larynx }\end{array}$} & \multicolumn{2}{|c|}{ Patients n $=26$} \\
\hline & $\mathbf{n}$ & $\%$ \\
\hline Normal & 18 & 69.23 \\
\hline Hyperemic & 6 & 23.07 \\
\hline Ignored & 2 & 7.69 \\
\hline Vocal Cords & $\mathbf{n}$ & $\%$ \\
\hline Normal & 23 & 88.46 \\
\hline Paretic & 1 & 3.84 \\
\hline Ignored & 2 & 7.69 \\
\hline Trachea & $\mathbf{n}$ & $\%$ \\
\hline Normal & 16 & 61.53 \\
\hline Hyperemic & 6 & 23.07 \\
\hline Tortuous & 1 & 3.84 \\
\hline With stenosis & 1 & 3.84 \\
\hline Hypotrophy & 1 & 3.84 \\
\hline Ignored & 1 & 3.84 \\
\hline Carina & $\mathbf{n}$ & $\%$ \\
\hline Normal & 23 & 88.46 \\
\hline Right skewed & 1 & 3.84 \\
\hline Ignored & 2 & 7.69 \\
\hline
\end{tabular}

Table 5. FB localization correlated with airways characteristics.

\begin{tabular}{cccc}
\hline Localization & \multicolumn{2}{c}{ Patients $\mathrm{n}=26$} \\
\hline Right Bronchus & $\mathrm{n}$ & $\mathbf{8 8 . 4 6}$ \\
Normal & $\mathbf{2 3}$ & 15.38 \\
Hyperemic & 4 & 65.38 \\
Both right and left & 17 & 23.07 \\
Just right & 6 & 42.31 \\
With stenosis & 11 & 7.69 \\
Left Bronchus & 2 & $\mathbf{3 . 8 4}$ \\
Trachea & $\mathbf{1}$ & $\mathbf{7 . 6 9}$ \\
Normal & $\mathbf{2}$ & 3.84 \\
With stenosis & 1 & 3.84 \\
\hline
\end{tabular}

occurred in patients with 56.22 median age, 67.87 median age when the FB was from vegetal nature and 74 years old when it was from metallic nature. When the FBs were teeth, the median age was 44.33 years old (Table 6). 




(a)

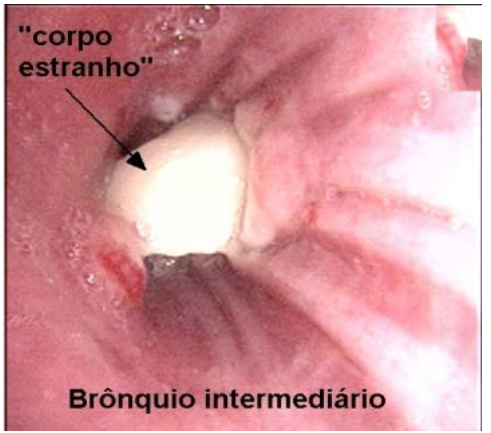

(d)



(b)

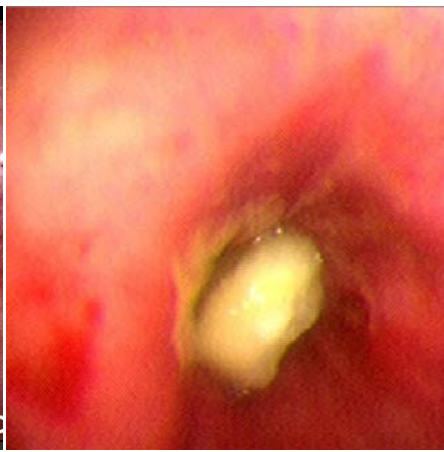

(c)

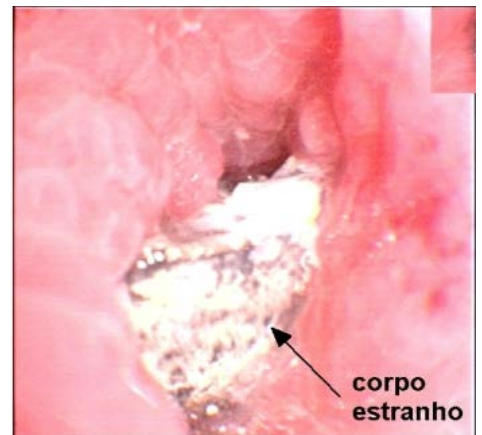

(e)

Figure 1. (a) A bone fragment found in right bronchus; (b) A bone fragment found in trachea with stenosis; (c) A corrn seed found in right bronchus; (d) A tooth found in right bronchus; (e) A metallic structure found in right bronchus.

Table 6. Occurrence of FB's nature according to patient's age.

\begin{tabular}{|c|c|c|}
\hline \multirow{2}{*}{ FB nature } & \multicolumn{2}{|c|}{ Patients $n=26$} \\
\hline & $\mathbf{n}$ & $\%$ \\
\hline Animal & 9 & 34.61 \\
\hline $21-30$ & 1 & 3.84 \\
\hline $41-50$ & 2 & 7.69 \\
\hline $51-60$ & 3 & 11.53 \\
\hline $61-70$ & 1 & 3.84 \\
\hline $71-80$ & 2 & 7.69 \\
\hline Vegetal & 9 & 34.61 \\
\hline $61-70$ & 6 & 23.07 \\
\hline $71-80$ & 1 & 3.84 \\
\hline $81-90$ & 1 & 3.84 \\
\hline Ignored & 1 & 3.84 \\
\hline Teeth & 3 & 11.53 \\
\hline $31-40$ & 2 & 7.69 \\
\hline $61-70$ & 1 & 3.84 \\
\hline Metallic & 3 & 11.53 \\
\hline $71-80$ & 2 & 7.69 \\
\hline Ignored & 1 & 3.84 \\
\hline Ignored & 1 & 3.84 \\
\hline $11-20$ & 1 & 3.84 \\
\hline
\end{tabular}




\section{Discussion}

Most of the studied patients were male, corresponding to $57.7 \%(n=15)$ of the cases, what is consistent to the literature [4]. In regard to aging, most of them were in the 61 to 70 age range, corresponding to $30.76 \%(n=8)$ of the cases. Second place in terms of frequency goes to the age range from 71 to 80 years old, corresponding to $19.23 \%(n=5)$ of the cases. In third place, the frequency was equal within 41 - 50 and 51 - 60 age ranges. The lowest incidences occurred in younger than 41 years old and older than 81 years old. This information shows that incidence rates increase with advancing age, what is consistent with the literature [2]. We could also perceive that only one patient was a child, age 11. Excluding this case, the mean age of the patients was 60.91 (+11.67) years, what is consistent with the age range found in most literature [6].

The ability to dignose endobronchial FB only with the characteristics of the respiratory tree is not trustable. After all, in most cases the respiratory tree was normal and without sputum, and in only a few of them it had non-specific signs, such as hyperemia and muco-purulent sputum. Images of the airway are also non-specific to diagnose FB. Therefore, the clinical history is the most important asset for the diagnosis of TFB and, once this diagnosis is a suspicion, we can indicate or not flexible bronchoscopy, as already done in medical practice [3].

In accordance with literature, most of the FB were found in the right bronchus, corresponding to $88.46 \%$ ( $\mathrm{n}=$ 23) of the cases, due to its anatomy [6] [9]. There were more cases of FB in the trachea, these ones corresponding to $7.69 \%(n=2)$ of all cases, than in the left bronchus, that happened in only $3.84 \%(n=1)$ of the cases. Considering that in one case of tracheal FB this organ was with stenosis, in normal conditions (without stenosis) both trachea and left bronchus had equal rate of FB localization (3.84\%).

In regard to the nature of the FB removed, animal nature and vegetable nature had equal frequency rate, each one corresponding to $34.61 \%(n=9)$ of the cases. Less frequent FB were teeth, corresponding to $11.53 \%(n=3)$ of the cases, and metallic FB, that also corresponded to $11.53 \%(n=3)$ of the cases. As seen, Inorganic FB corresponded to $62.5 \%$ of the cases and organic FB corresponded to $37.5 \%$. In this aspect our study disagreed with literature, that reported inorganic FB in $20 \%(n=3)$ of the cases and organic in $80 \%(n=12)$, what can be related to variety of the analyzed people. We found in our study that patients with FB from metallic and vegetal nature were older than patients with FB from animal nature or with teeth as FB [4] [6] [9].

In other studies, FB extraction with flexible bronchoscopy was successful in $82.5 \%$ to $90.7 \%$ of the cases, and rigid bronchoscopy was required in only $15 \%(n=6)$ [6] [9]. In our study, the procedure was successful in $80.76 \%$ $(n=21)$ of the cases and rigid bronchoscopy was required in only $19.23 \%(n=5)$ [6]. We found that the rigid bronchoscopy was a better procedure in two cases: one with stenosis of trachea and another with stenosis of right bronchus, where the flexible bronchoccopy was not possible to advance through the stenosis. In another two of these cases the success was achieved in the second trial of flexible bronchoscopy. This rate was higher than the ones found in some studies, which found success in $60.86 \%$ of the cases [3].

Many complications can occur after FB extraction: edema, hemoptysis, pneumothorax, tracheoesophageal fistula, pneumonia, atelectasis, fever, and respiratory failure [6] [10]. None of the patients in our study presented with bleeding, and in one case (3.84\%) we did not have access to this kind of information. There were no other complications in the reports. As shown in other studies, complications are rare [3].

We conclude that our study is consistent with literature, showing high success rate in the removal of TFB in adults with flexible bronchoscopy, with low incidence of complications.

\section{References}

[1] Qureshi, A. and Behzadi, A. (2008) Foreign-Body Aspiration in an Adult. Canadian Journal of Surgery, 51, E69-E70.

[2] Boyd, M., Chatterjee, A., Chiles, C. and Chin Jr., R. (2009) Tracheobronchial Foreign Body Aspiration in Adults. Southern Medical Journal, 102, 171-174.

[3] Limper, A.H. and Prakash, U.B. (1990) Tracheobronchial Foreign Bodies in Adults. Annals of Internal Medicine, 112, 604-609.

[4] Ramos, M.B., Ferna'ndez-Villar, A., Rivo, J.E., Leiro, V., García-Fonta'́n, E., Botana, M.I., et al. (2009) Extraction of Airway Foreign Bodies in Adults: Experience from 1987-2008. Interactive CardioVascular and Thoracic Surgery, 9, 402-405. http://dx.doi.org/10.1510/icvts.2009.207332

[5] Fraga, A. de M. A., et al. (2008) Aspiração de corpo estranho em crianças: aspectos clínicos, radiológicos e tratamento broncoscópico. Jornal Brasileiro de Pneumologia, São Paulo, 34, 74-82.

[6] Rodrigues, A.J., Oliveira, E.Q., Scordamaglio, P.R., Gregório, G., Jacomelli, M. and Figueiredo, V.R. (2012) Broncos- 
copia flexível como primeira opção para a remoção de corpo estranho das vias aéreas em adultos. Jornal Brasileiro de Pneumologia, 38, 315-320. http://dx.doi.org/10.1590/S1806-37132012000300006

[7] Boyd, M., Chatterjee, A., Chiles, C. and Chin Jr., R. (2009) Tracheobronchial Foreign Body Aspiration in Adults. Southern Medical Journal, 102, 171-174.

[8] Ikeda, S., Tsuboi, E., Ono, R. and Ishikawa, S. (2010) Flexible Bronchofiberscope. Japanese Journal of Clinical Oncology, 40, e55-e64.

[9] Mise, K., Jurcev Savicevic, A., Pavlov, N. and Jankovic, S. (2009) Removal of Tracheobronchial Foreign Bodies in Adults Using Flexible Bronchoscopy: Experience 1995-2006. Surgical Endoscopy, 23, 1360-1364. http://dx.doi.org/10.1007/s00464-008-0181-9

[10] Li, Y., Wu, W., Yang, X. and Li, J. (2009) Treatment of 38 Cases of Foreign Body Aspiration in Children Causing Life-Threatening Complications. International Journal of Pediatric Otorhinolaryngology, 73, 1624-1629. 
Scientific Research Publishing (SCIRP) is one of the largest Open Access journal publishers. It is currently publishing more than 200 open access, online, peer-reviewed journals covering a wide range of academic disciplines. SCIRP serves the worldwide academic communities and contributes to the progress and application of science with its publication.

Other selected journals from SCIRP are listed as below. Submit your manuscript to us via either submit@scirp.org or Online Submission Portal.
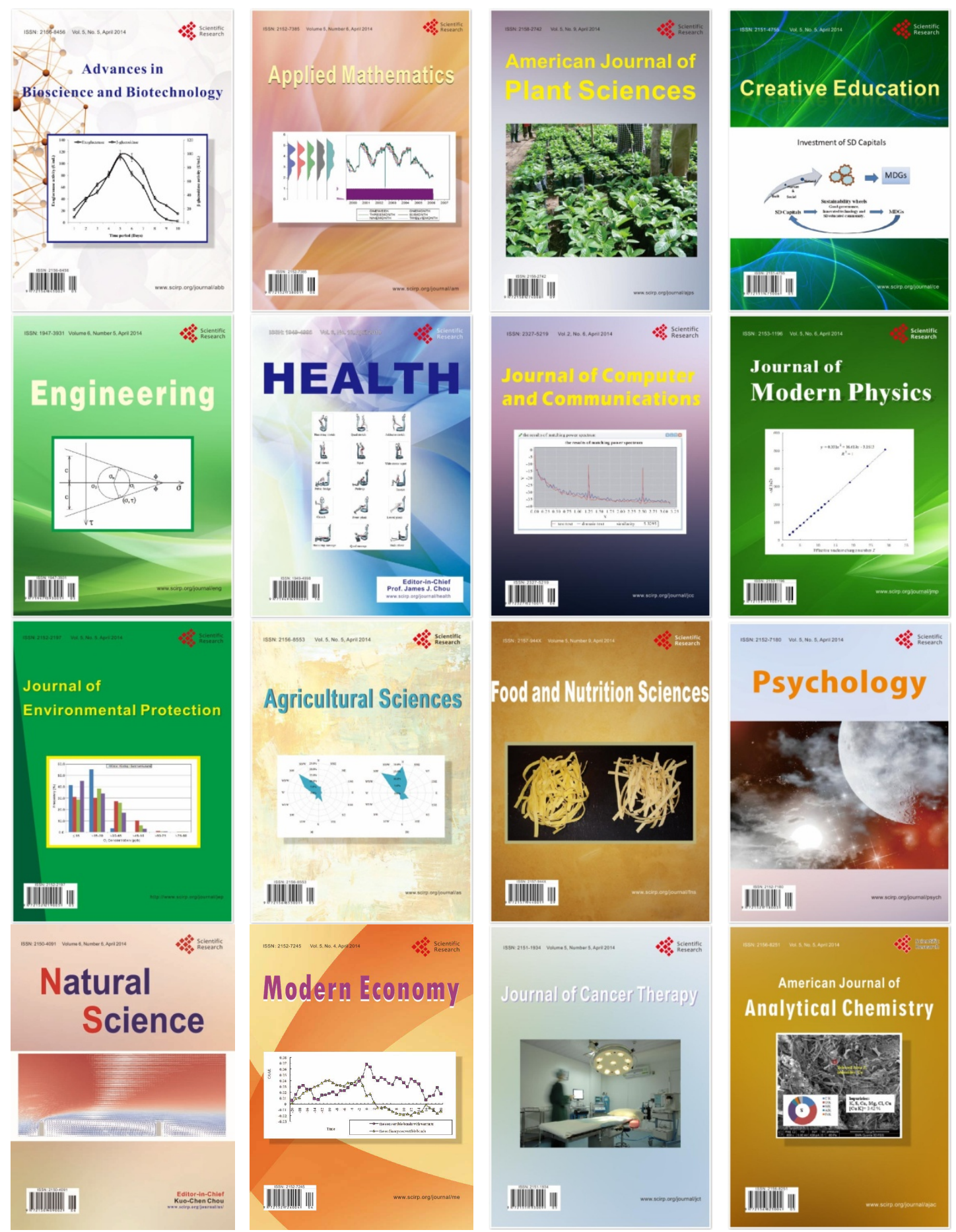